\section{A I \\ oN}

\section{THE OPERATIONS FOR CANCER OF THE TONGUE.}

BEING AN APPRECIATION OF THE WORK OF THE LATE Sir Henry BUtLin.*

BY

W. G. SPENCER, M,S., M.B., F.R.C.S., SURGEON TO THE WESTMINSTER HOSPITAL.

A $\mathrm{T}$ a lecture given liere a year ago on the inflammatory conditions of the mouth and tongue which precede cancer, I showed a number of sections under the microscope to illustrate the teaching of Sir Henry Butlin. I propose to-day to review the work by which he advanced the surgery of the tongue, not only by rendering the removal of cancer less unsuccessful, but what is much more important, by describing how the onset of the disease may be anticipated and prevented.

The clinical diagnosis of cancer of the tongue is liable to err in both directions, and Butlin was one of the first to cmploy the microscope as the essential means of confirming or varying the conclusion reached by clinical observation. Before Butlin's demonstration surgeons had not generally acknowledged the value of the microscone. This may be partly explainedby the imperfect preparation of the material to be examined. A glance through the illustrations of microscopic specimens contained in the volumes of the Pathological Society's Transactions will give a very good idea of the gradual improvement in pathological histology by which the minute structure came to be demonstrated. In his first communication-in the Transactions for 1877-Butlin gave illustrations of an enchondroma of the submaxillary salivary gland which would not be recognized by the present-day student. There is a very marked advance in the -next paper-in the Medico-Chirurgical Society's Transactions, 1878-in which he gave the first description of chronic superticial glossitis, a name previously used by Fairlie Clarke for the clinical appearances, although Clarke had not made any microscopic examination. Butlin, in his Sarcoma and Carcinoma, 1882, more clearly illustrated this most im. portant condition and the clianges by which it passed over into epithelioma. In 1879, in the Proceedings of the Royal socicty and in the St. Bartholomew's Hospital Reports, he gave the results of his microscopical examination of the fur on the tongue; the only additions since have been connected with the examination of the microorganisms contained in the fur, and on this definite knowledge is still lacking.

Butlin commenced operating on the tonguo in 1881. In 1883 he noted the value of weak solutions of chromic acid for secondary sypliilitic lesions in combination with the administration of mercury. In 1885 appeared the first edition of the Diseases of the Tonguc, which was translated both into French and German. In 1888 he nuade an important advance by recommending the cutting out of obstinate gummata and tertiary ulcers. He also described sarcoma of the tongue - a condition so rare that he hesitated to come to general conclusions on the matter. In 1890, as the result of obserrations on two thyreoglossal tumours of the base of the tongue, he counselled an expectant attitude and a limited operation, in view of the dangei, if the thyroid gland be ill-developed, of setting up myxoedema. In 1889 he more fully described the inflammatory conditions preceding cancer. He had come to supplement regularly the conclusions arrived at from his clinical experience by the microscopical examination of the disease after remoral.

The importance of the microscopical examination has, however, even yet not been fully accented. I am sorry to say that its omission in many cases shows a comfortable satisfaction in the all-sufficiency of clinical observation, and, in spite of what has been said for it, that which some call Bioscopy is the one thing often neglected until

"Deliverod at the Medical Graduates' College and Polyclinic on June 11 th, 1912 . too late. On the other hand, confusion has been caused by conditions being styled epithelioma which have dis appeared under non-cperative treatment.

Later on Butlin submitted a number of cases to more thorough examination by Dr. Bashford, assisted by Dr. Murray, of the Imperial Cancer Research, and he described in later communications how many of the conditions he had previously termed precancerous, proved to be cases of early epithelioma. Sniall indolent ulcerations, apparently quite superficial, exhibited under the microscope epitheliomatous cells descending among the muscle fibres. On the other hand, quite recently within my own experience, the presumptive diagnosis of epithelioma has been corrected by the microscope to angioma, tuberculoma, or simple ulceration.

Butlin's name is most generally connected with the operation at two sittings for the removal of cancer of the tongue, which he began in December, 1895. By it he obtained results far beyond those published by other surgeons; I will emphasize the importance of his method directly. But, after all, it is a method to be adopted for epithelioma-cancer which has already set in; even if the disease is early and the patient remains free from any sign of return of the disease, yet there is always some remnant of anxiety as to the possibility of late recurrence. Now, long before he described this method of operating for epithelioma, Butlin had advocated the excision of patches of lenkoplakia, warty and nodular plaques, irritable scars, and indolent ulcers on the tongue, to be followed by a thorough examination of sections under the microscope. And we ought to estimate this excision of patches at a far higher value as preventing cancer. The operation is free from risk ; it does not leave a deformity nor impairment of speech, and if after examination the disease proves not to be cancer, all cause of anxiety disappears. Above all things, an excision of the patch completes the diagnosis, and should it be found, however unexpectedly, after an examination of a series of sections, that epithelioma has really begun, then the second stage, the dissection in tho neck, can be undertaken without any deiay.

The particular grounds for delay in adopting a radical line of treatment formerly were the application of caustics and the undue prolongation of the administration of the mercury and potassium iodide. As to the application of caustics, this practice has not entirely disappeared, and recently instances have come under notice in which this both useless and harmful procedure has appeared to directly excite the onset of cancer. As to the administration of mercury and potassium iodide, Butlin urged that an effect should be evident within ten days, not so much by the relief of symptoms, as by the actual healing and disappearance of the lesion, and when this end has not been attained within three weeks the antisyphilitic remedies should not be continued. The more intensive treatment now practised, whether mercury injection or inunctions, or injections of salvarsan, should have an even more rapid effect, and there should be therefore less excuse for any undue delay. These measures, if they do so at all, produce a decided effect at once. And yet the excising of patches and scars to prevent cancer seems at present to be more neglected. Cases drift on until some large, dangerous, and deforming operation is required. Hence the question of radical treatment is still involved in a vicions circle. The practitioner has only a terrifying operation in view, and to aroid it advises the trial of one treatment after another. Thins the simplest and quickest way of getting rid of the disease is overlooked.

Saliarsan has proved a very important adjursnt to mercury in the treatwent of the severe forms of sacondary syphilis attacking the mouth and throat. And in combination with a more thorough exhibition of mercury, salvarsan can aid in preventing the development of later syphilitic lesions. It may thus be an indirect means of preventing cancer. But salvarsan has now been given often enough to prove that it has no effect upon the inflammatory lesions which immediately precede canccr, and which Butlin urged should be excised. Its administration in such cases is not only a waste of time, but also diverts attention away from the one means of cure. As there is some small risk in the administration of salvarsan, there is possibly more danger in its administration than the excision of the patch under a general anaesthetic. Radium and light rays appear to have a superficial antiseptic effect, and so afford 
some relief, which does not appear to differ from such as can be more easily attained by painting on a suitable antiseptic fluid at frequent intervals. But in addition to the effect on the surface, koth radium and light rays tend to excite the growing margin of true squamous-celled carcinoma and to incluce a videspread and rapid infection of the corresponding lymphatic glands, which soften, break down, and develop into large excavations in the neck, or by the spread of the glandular enlargement to the root of the neck and mediastinum produce respiratory obstruction. Meanwhile the primary growth seems to spread rapidly down the mucous membrane of the fauces. Sébileau has described a case in which a papilloma on the tongue had existed for twenty-five years; on exposure to radium it rapidly became malignant. Other cases have been recorded, or have been heard of, or have come under my dircet observation. In spite, therefore, of newer alternatives, we ought to follow Butlin in the excision of any lesion which fails to heal in three weeks after the removal of a tooth, the cessation of smoking, the administration of antisyphilitics, or any other form of treatment.

When on examination an excised patch or ulcer shows that epitheliomatous columns have begun to grow down into the muscle fibres it is necessary in all cases to urge the dissection required to remove the glands from the neck which may possibly have become infected. Repeated instances have occurred of late in which this has nct been done, and the disease has shown itself within a year in the corresponding lymphatic glands. If the epithelioma is strictly limited to the tongue on one side and has not encroached upon the middle line or the tip or the front of the floor of the mouth, then the dissection should be done on one side only. In operating one should remove tho glands in the submaxillary region without interfering with the mylohyoid muscle or hypoglossal nerve, and one should avoid opening a communication with the moutl behind the mylohyoid by leaving the submaxillary duct and the intrabuccal portion of the salivary gland. It is necessary, however, to remove any prolongation of the submaxillary gland along the facial artery as it turns up over the ramus of the jaw. The submental glands on each side of the middle line should be also excised, unles; the disease is far back to one side. Especially in this last case the incision must include the lower end of the parotid gland and the septum of tissue between it and the submaxillary, otherwise infected lymphatic tissue will be left behind further, the sterno-mastoid muscle must be well retracted so that all deep cervical glands may be dissected from the frort of the blood vessels, extending from the mastoid process down to the crossing of the omohyoid. Generally in early cases it is unnecessary to go further. As to a dissection of both anterior triangles it is required when the tip or floor of the mouth in front is involved, and, of course, when the disease lies arross the middle line. The wound should be drained fro:n the mastoid angle because of the opening of the parotil capsule and the cutting across of the submaxillary duct.

Then, if only a small patch has been removed from the mouth, the resulting deformity is limited to the scar in the neck. There may be at first a slight weakness of the angle of the morth, which passes off ; if the lowest branch of the facial nerve can be spared this may not occur. Tho main objection to operating in two stages is the getting of the patient to submit to the second operation. One may avoid this by the aid of a microscopist, who at the operation can prepare a fresh section. Epithelioma being found, the dissection in the neck can be proceeded with.

For cases in which epithelioma has made some progress the removal of a part, a half, or even the whole of the tongue, through the mouth by Whitehead's method, is required. In doing this Butlin preferred the turning of the head to one side in place of Whiteliead's half-sitting posture in a rocking chair, or the hanging-head position which is attended by so much venous haemorrhage.

The operation through the moath is contraindicated when the tongue cannot be well freed and the disease brought outside the line of the teeth. Butlin added to the scope and safety of the intrabuccal operation by inserting beforehand a laryngotomy tube. Of course preliminary laryngotomy may be unnecessary when the mouth can be gagged widely open, when the anaesthetic administration goes smoothly and the light is good. I do not know whether any one follows Whitehead in twisting the lingual artery; at any rate, aseptic ligatures are the rule. These ligatures should arrest most of the haemorrhage, and the suturing over of raw surfaces largely controls the subsequent oozing. The additional advantage of suturing in getting primary healing is obvious. One may sometimes obtain a flap of mucous membrane from the floor of the mouth. There is a difference of opinion as to the turning back the tip when half the tongue has been taken away. The raw surface is thus closed over, and the stump is rendered more mobile, but for a time the patients make but an awkward use of it.

Whenerer the floor of the mouth is involived to any extent, an intrabuccal operation becomes unsuitable. A submaxillary operation is then required, such as that of Kocher's earlier method, or some modification. For in such cases the infection must be assumed to have spread directly through the mylohyoid and hyoglossus (Cheatle) muscles, also the sublingual and intrabuccal portions of the submaxillary salivary glands are involved.

Both carotid triangles should be dissected out at a second operation, for a crossed intection may be assumed when the floor of the mouth is involved, unless it be far back near the tonsil and quite limited, when the question of dissecting the posterior triangle of the same side may come up for consideration.

To get the patient to submit to these two operations some surgeons have commenced with the neck. Butlin did not follow this, and I may quote a recent case published by Morrestin in which, after he had excised the glands from the neck, the wound became infected from the epithelioma in the mouth, septic thrombosis spread up the internal jugular into the skull and caused the patient's death.

If the patient will probably decline the second operation it is better to do all at once, even although at a somewhat increased risk.

The two additions to the foregoing procedures, which should not be adopted without very good reason, are a division of the cheel and of the jaw. 'As for the cheek', its division leaves a marked and obvious scar, which may be followed by considerable limitation of movement from the formation of scar tissue in the masseter. A division of the jaw introduces a serious complication. All statistics show a very marked increase in the mortality from it, for it disturbs deglutition and induces pneumonia; also, there is a great tendency to a limited necrosis and a delay in healing.

The division of the jaw in the miadle line and the separation of the rami, a prosedure connected with the names of Sédillot aid Syme, has been resuscitated by Kocher. I hold strongly that one should employ modifications and extensions of Kocher's first method, and only exceptionally follow his second proposal. If the growth has not only invaded the floor but has become even loosely attached to the jaw, then, unfortunately, the jaw must be assumed to have become invaded, and an excisicn is necessary. The only limited excisions at all satisfactory are those near the synphysis not involving the masseters or internal pterygoids. When towards one side, the excision should include both the horizontal and vertical ramus behind the canine teeth, preserving the genial region, for then the stump of the tongue remains mobile, and the movement of the jaw on the opposite side is not limited.

I will now briefly note the results of operations for the removal of epithelioma. As far as regards the irnmediate recovery from the operation, Whiteliead had no deaths among 50 cases of large excisions of the tongue. The glands in the neck were left untouched, and the majority of the cases died of glandular infection. A ferv survived to be reckoned as cured, but no sufficient details were published of the microscopical examinations of the disease. In 1894 Butlin gave a clinical lecture on forty-six cases of removal of one half or the whole of the tongue with ons fatal result. If we combine the results published by various surgeons since 1900 , we arrive at the conclusion that the average mortality from the operation, if all the severe cases are included, is about 25 per cent., that of those who survive the operation more than 10 per cent. remain alive and free from the disease three years after the operation.

Butlin's results were very much better. He calculated 
that from 1881 to 1908 be operated upon 200 patients, of whom 20 died of the operation and one was lost sight of. Of those who survived the operation, 47 suffered from recurrence in the mouth, and 44 from recurrence in the glands in the neck without recurrence in the mouth. Two died from a crossed infection of the gland on the opposite side of the neck, in one the cancer reappeared on the opposite border of the tongue, one died of secondary infection of the lungs. In 8 cases the operation was partial or abandoned; 22 were alive and well or had died of some other disease within three years of the operation, 6 being alive and well one year after the operation. There remained 57 who were alive and free from recurrence three years or more after the operation. In brief, Butlin obtained a definite success in 32.76 per cent., with an immediate mortality of 10 per cent.

In 70 cases the disease on the tongue had been removed, and in addition the glands from the neck. Of these, 6 died from the operation, and 24 werc alive and well over three years from the operation, or 42 per cent. With these Butlin compared 54 cases in which the glands had not been removed, and they wore, on the - whole, less severe cases. Yet, owing to the tendency to glandular infection, only 12 were alive and well after three years from the operation, or 29.26 per cent.

Poirier in 1901 commenced to follow Butlin, and in 1907, out of 32 cases, 5 were alive over three years from the operation; or 15.3 per cent. The mortality from the operation is directly proportional to its severity, but there are other complicating factors which add to the mortality among the less severe cases. Practically all the patients are over 40 , and the majority over 50 ; those below 40 are all very malignant cases. Also syphilis, even although its previous inanifestations have been slight, has an important influence through the blood ressels of the heart, lungs, and brain, and is responsible for fatalities from heart failure, pneumonia, and cerebral haemorrhage and thrombosis.

'The danger of haemorrhage, whether primary or secondary, can practically be ayoided if one considers inopierablc all cases which would entail interference with the common or internal carotid arteries. The ligature of the external carotid well beyond its origin, or, safer still, the soparate ligature of the lingual and facial arteries, avoids any severe primary haemorrhage, and such ligations are free from dangers of secondary haemorrhage, even although.there should be suppuration in the wound. The only cases recently reported of death from secondary liacmorrhage were due to ulceration into the carotid occasioned by an oesophageal tube kept in for feeding; both occurred on the tenth day after operation.

A ligature and excision of a portion of the internal jugular vein is generally free from the danger of secondary haemorrhage or thrombosis, although the case reported by Morrestin shows that it may occur. But it becomes very dangerous if the internal jugular on the opposite side has already become occluded or compressed.

Recurrence may show itself in the scar of the tongue, in glands beyond the area of the operation, or by a diffuse and general infiltration. In the last case all further operation is definitely contraindicated. If glands begin to enlarge beyond the area previously dissected, for example, in the posterior triangle of the same side, or in the opposite side of the neck, then a further free dissection in the neck may arrest the disease. I can speak of cases which have continued well after such a secondary operation.

Recurrence in the stump of the tongue, whether early or late, is generally unfavourable, and a further operation is usually contraindicated. The sort of case which may be bencfited by a secondary operation is one in which there has been extensive leukoplakia, but with only a limited epithelioma. At the first operation as much as possible of the tongue has been preserved to avoid deformity. Then a complete removal of the rest of the tongue along with a thorough dissection in the neck may save the patient.

Inoperable cases are especially relieved by disinfecting the surface of the growth by painting on frequently a non irritating but powerful antiseptic. I have generally used 1 in 1,000 mercuric cyanide painted on every four hours, and the mouth afterwards washed out with alternatively hydrogen peroxide or potassium permanganate in as strong solution as can be borne.

liadium and light rays have proved disappointing, as mentioned above; they hurry on the glandular enlargement. On the other hand, this does not seem to result from heat induced by the high frequency current. The heat cauterizes the surface and penetrates deeply, but does not cause such a deep slough as the actual cautery, nor does it stimulate excessively the glandular disease. In favourable cases a skinning orer of the growth results, to the great relief of the patient.

The application of radium and light rays involves repeated sittings, and $I$ have known great pain and faintness follow. The application of the high frequency current, termed "Diathermy," is done once under au anaesthetic.

To summarize what has been said, the late Sir Henry Butlin taught us that the excision of any versistent patch or indolent ulcer is the means for preventing the onset of cancer of the tongue. The operation is quite safe, is not followed by any deformity, and as soon as the tissue removed has been examined the patient may be assured of his safety. Further, the early excision of an epithelioma of the tongue, followed by excision of the glands in the neck, is for early cases not dangerous, and in Butlin's hands as many as 42 per cent of such were alive and free from recurrence three years after the operation. If these cases are advised to submit to early operation onc will not have to regret that cases reach an advanced stage, when severe, deforming operations become necessary. Yet I might quote any number of single cases, which have been exhibited by various surgeons, alive and well more than three years after such operation.

Sir Henry Butlin made a great advance; there is a need for much more. As he remarked, the majority of cases operated upon die of the disease, and the Registrar. General's statistics state that more than 750 people die annually in England and Wales of cancer of the tongue.

BIBLIOGRAPHY

Diseases of the Tongue. Cassell and Co., London. 1885. Re-

rankheiten der $Z$ unge. Deatsch tearbeitet und herausgegoben von Julius Beregszaszy. Wien. 1887. W'. Braumuller. Pp. 402, 8 plates, 8vo.

Maladies de la Langue. Traduit de 1'Anglais par Douglas-Aigy'e. Paris. 1889. Lecrosnier et Babé. Pp. 424, 8vo. New and
enlarged edition, 1900 . Enchrondroma of the Submaxillary Salivary Gland. Trans. Path. Soc., 1877, xxvili, 228 .

Pathology of Chronic Superficial Glossitis. Trans. Med.-Chir. Soc. $1878,1 \times 1,51$.

Fur on the Tongue. Proc. Roy. Soc., 1879; St. Bartholomew's Hospilal Reports, 1879, xv, 37

(1883, xxx, 175

Gummata and Tertiary Ulcers of the Tongue. St. Bartholomeri. Hospital Reports, 1888, xxiv, 83 .

Leukokeratosis. Illustrated Med. Neus, 1889, ii 289

Precancerous Conditions of the Tongue. BRITISH MIeDICII JOURNAL, 1889, $i, 777$.

Two Cases of Thyreoglossal Tumours of the Tongue. Trans. Clin. Soc., 1890, xxiii, 118 .

A Clinical Lecture on a Series of Forty-six Cases of Removal of One-half or the Whole of the Tongue, with one Fatal Result. BRITISH MEDICAL JoURnal, 1894, i, 785.

Hunterian Lecture: On what Operation can do for Cancer of the The Onue. British Medical Jodral, $1898, i, 541$.

The Operative Surgery of Malignant Disease.

the Special Causes of Death during and after Operations on Pre Mouth and Throat, and the Best Means of Arresting by Preliminary Laryngotomy. Clinical Journal, 1902-3, xxi, 113 . On my Cnsuccessful Operations for Cancer of the Tongue and the Early Diagnosis of the Disease. British Medical Jovrnal.

Dartity in the Diagnosis of Cancer of the Tongue. Practioner, On Remos, 5 . Contents of the Anterior Triangle of the Neck in Cases of Malignant Diseases of the Tongue. JOURNAL, 1905, i, 285

Illustrations of Very Early Conditions of Cancer of the Tongue. BRITISH MEDICAL Jodrnal, 19C6, i, 1201.

An Address on the Results of Operations for Carcinoma of the Tongue, with an Analysis of 197 Cases. Delivered before the International Surgical Society in Brussels, September, 1908. On the Farly Diagnosis of Cancer of the

Proc. Thene and on the Results Section. 1909 , ii 99 .

Burghard's System of Operative Surgery, 1909, ii, 205

THE Sixth International Congress of Obstetrics and Gynaecology will be held at Berlin in September next (9th to 13th), under the presidency of Professor Bumm. 'The principal subjects proposed for discussion are the treatment of peritoneal wounds and the surgical treatment of uterine haemorrhage in pregnancy, childbirth, and after confinement. There will be an exhibition in connexion with the congress. 